\title{
Las élites políticas en el espejo: perfiles socioprofesionales de los elencos dirigentes argentinos (1983-1999)
}

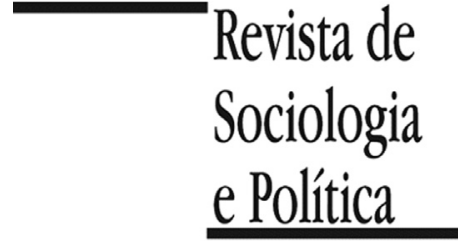

DOI $10.1590 / 1678-987318266604$

\section{Virginia Mellado' (iD}

RESUMEN Introdución: El propósito principal de este artículo es examinar las características socioprofesionales de la dirigencia político partidaria argentina en un periodo caracterizado por la estabilidad democrática y la competencia electoral (1983-1999). El estudio se basa en el análisis del reclutamiento del personal político en una provincia del interior argentino (Mendoza), para indagar la procedencia social y grupal de los dirigentes, lo que permite reconstruir el mapeo de carreras políticas posibles en el ámbito nacional y provincial. La hipótesis de partida fue que la recurrencia regular de elecciones y la competencia electoral desplegada luego de 1983 constituyeron factores contextuales que favorecieron el desarrollo de un ejercicio profesionalizado de la actividad política. Métodos: Basada en el método prosopográfico, la investigación se ha llevado a cabo a partir de la construcción de una base de datos de 544 entradas por cargos alcanzados, que incluyó a diputados y senadores nacionales, ministros, gobernadores, legisladores provinciales, entre otros. Las fuentes para la construcción de esta base provienen de documentación del Congreso Nacional de Argentina y de la Legislatura de Mendoza, de la prensa y de entrevistas en profundidad a dirigentes políticos claves. Resultados: Los principales resultados que arrojó el análisis de variables cuantitativas, como la edad, la composición por género, el nivel educativo y las ocupaciones de origen exhibieron los canales de reclutamiento de las élites políticas a partir de los diferentes espacios sociales. Discusión: El derrotero de esta investigación se halla en contribuir a examinar la dirigencia que ha integrado los gobiernos democráticos en sus distintos niveles en Argentina, con el objeto de observar tanto la forma en que se gestan las creencias entre los grupos que toman decisiones políticas como la forma en que se constituyen y estructuran las redes de poder entre políticos, funcionarios y personal administrativo. La mirada de conjunto dio cuenta de los atributos o condiciones que facilitan u obstaculizan las carreras políticas en el periodo contemporáneo, por lo que se procura contribuir al debate en torno a la profesionalización de la política y los políticos en América Latina.

PALABRAS CLAVE: élites políticas; profesionalización; democracia; reclutamiento; prosopografía.

Recebido en el 12 de Abril de 2016. Aprobado en el 23 de Enero de 2017.

\section{Introducción ${ }^{1}$}

${ }^{1}$ Agradezco las sugerencias y comentarios de los evaluadores anónimos de la Revista de Sociologia e Política.
$\mathrm{L}$ a recuperación de la democracia en 1983 en Argentina, luego de siete años de dictadura militar, fue interpretada mayoritariamente como un "momento fundante" (Gargarella, Murillo \& Pecheny 2010). Para los contemporáneos, la democracia parecía constituir la medida y la posibilidad de crear un orden político nuevo que tuviera escasas conexiones con el pasado. No obstante, a partir de la distancia histórica, 1983 aparece como una mixtura entre lo "nuevo" y lo "viejo"; entre una sociedad que buscaba mirar al futuro gracias a la promesa democrática, pero que no había logrado doblegar muchos de aquellos actores que habían hecho imposible el juego democrático durante gran parte del siglo XX (Halperin Donghi 1994).

Por ello, la coyuntura de 1983 representa un punto de partida eficaz para explorar todo aquello que persiste y que cambia, un momento histórico que puede ser interpretado como "una coyuntura de cambio" (Cantón 1966). La democracia, y especialmente su estabilidad, modificaron algunas de las reglas que habían dominado el juego político argentino desde los años '30, en particular, para quienes tenían la vocación o aspiraban a dedicarse a la actividad política de manera profesional. En consecuencia, el objetivo principal de esta investigación se encuentra en examinar cuáles han sido los perfiles que describe 
${ }^{2}$ La provincia de Mendoza se encuentra ubicada en el centro-oeste de la República Argentina. Cuenta con una extensión de $148.827 \mathrm{~km}^{2}$ y una población de 1.738 .929 habitantes. la dirigencia político-partidaria argentina en un periodo caracterizado por la estabilidad democrática y la recurrencia regular a elecciones, tal como el exhibido luego de 1983. En particular, el análisis se basa en el reclutamiento del personal político de una provincia del interior argentino, la provincia de Men$\mathrm{doza}^{2}$, para observar el abanico amplio de carreras políticas, que se desarrollan tanto en la órbita provincial como nacional.

El análisis de los perfiles de la dirigencia política de una provincia argentina remite a una problemática vinculada con el proceso de la transición democrática: la profesionalización de la política y los políticos. En efecto, para quienes querían forjar una carrera profesional, es decir, quienes buscaban dedicarse intensamente por periodos largos de tiempo a la política (Alcántara Sáez 2013), la estabilidad democrática era la principal condición de posibilidad. La recurrencia regular de elecciones y la competencia electoral sucedida luego de 1983 son factores que permiten llevar a cabo un ejercicio a partir del cual se puede medir la especialización de los cuadros políticos en la actividad. En consecuencia, la profesionalización política está relacionada aquí con las máximas weberianas de vivir "para" y "de" la política (Weber 1972). La profesionalización se vincula con la especialización en política, es decir, con la adquisición de habilidades particulares dentro de este campo de actividades como la experiencia en producir legislación solvente o dominar un campo de conocimiento o saber específico ligado con la administración y las políticas públicas (Jones et al., 2002).

La selección de este caso anclado en la escala provincial se fundamenta en que el mismo ofrece indicios sobre la heterogeneidad de carreras posibles y amplía la mirada no sólo a las carreras legislativas, para los que ya se cuenta con algunos estudios pioneros (Lodola 2009), sino también a las que se desarrollan en relación a los cargos ejecutivos y técnicos provinciales. El anclaje subnacional, si bien presenta la limitación de la comparabilidad, favorece el examen "denso" en un sistema multinivel como el argentino. Asimismo, la escala provincial se justifica a partir de la estructura de partidos que ha adoptado la Argentina luego de 1983, donde se ha acentuado un proceso de territorialización, dando lugar a un fenómeno de fragmentación partidaria (Calvo \& Escolar 2005; Leiras 2007; Mustapic 2013). Los partidos se organizan de acuerdo a líneas federales y, por consiguiente, el sistema argentino "se caracteriza por la existencia de una constelación de organizaciones partidarias a nivel subnacional" (Almaraz 2010; Benton 2003). El conjunto de las carreras políticas, incluso las ejercidas a nivel nacional, están centradas en las provincias y se estructuran a partir de ellas. Tanto la selección de las candidaturas para los cargos de diputado y senador nacional, como las elecciones que dirimen los cargos nacionales están basadas en reglas que cada provincia determina. Como ha destacado una abundante literatura, esta pregnancia de la escala subnacional se debe a que "el locus de la política partidaria en Argentina es la provincia", donde los actores concentran su base de apoyo para posicionarse a nivel nacional (Jones et al., 2002; Benton 2003; Lodola 2009; Gibson \& Suarez Cao 2010).

Con todo, el derrotero de esta investigación se halla en contribuir a examinar la dirigencia que ha integrado los gobiernos democráticos en sus distintos niveles en Argentina, con el objeto de observar tanto la forma en que se gestan las creencias entre los grupos que toman decisiones políticas, como de las redes de poder construidas a partir de los lazos entre dirigentes políticos, funcionarios y personal administrativo (Sawicki \& Mathiot 1999). La mirada de conjunto da cuenta de los atributos o condiciones que facilitan u obstaculizan las carreras políticas en el periodo contemporáneo, por lo que se procura contribuir al debate en torno a la profesionalización de la política y los políticos en América Latina. 
La pregunta por los perfiles de las élites político-partidarias y de los grupos de poder ha constituido una problemática clásica dentro de los estudios de la sociología, la historia y la ciencia política (Bourdieu 1981; Eulau \& Koff 1962; Gaxie 1980; Weber 1972; Wright Mills 1957). Si bien los estudios sobre el reclutamiento de los elencos dirigentes han integrado la agenda de investigadores argentinos y latinoamericanos (De Imaz 1964; Cantón 1966), en los últimos tiempos, ha habido una proliferación de estos estudios, preocupados por caracterizar sociológicamente a quienes han integrado las más altas posiciones de poder, riqueza y prestigio (Losada 2008; 2009; Hora 2002; Canedo 2002; Coradini 2001; Siavelis \& Morgenstern 2008; Jones et al., 2002; Vommaro 2015). Para el caso argentino, los estudios que se han enfocado en el periodo contemporáneo han analizado el reclutamiento del Congreso Nacional, de los gobernadores, al igual que la composición de ciertos ministerios nacionales (Canelo 2011; 2013; Dalbosco 2003; Heredia, Gené \& Perelmiter 2012; Giorgi 2014; Perelmiter 2012). Asimismo, han explorado la composición de Legislaturas provinciales de los principales centros urbanos del país con el propósito de hallar pautas de análisis de los actores de poder (Lodola 2009; Ferrari 2008; Mellado 2016a; Vommaro 2015).

El análisis de los perfiles se ha realizado a partir de la utilización del método prosopográfico (Stone 1971; Ferrari 2010). Este instrumento analítico, que ha sido corrientemente puesto en práctica para analizar las élites políticas en distintos momentos históricos, resulta altamente apropiado para caracterizar a un grupo social o de individuos con el objeto de examinar su background social (Stone 1971). A partir de la delimitación de un grupo de personas que integran un actor colectivo, se somete al conjunto a un cuestionario común para conocer sus características - tales como la edad y la nacionalidad - y sus atributos - tales como el nivel educativo y la profesión. Asimismo, la herramienta permite indagar los itinerarios sociales dentro de un campo (Ferrari 2010), lo que posee un alto valor heurístico al lograr vincular trayectorias individuales y organizacionales.

De acuerdo a este protocolo se confeccionó una base datos de 544 entradas por cargos alcanzados. El personal político que integra el corpus que ha servido de base para este estudio se ha circunscripto a diputados y senadores nacionales por Mendoza, gobernadores y vice de la provincia, diputados y senadores provinciales y ministros de gobierno de la administración provincial durante el periodo 1983-1999. Es decir, se ha colocado el foco en el examen de los cargos electivos y de aquellos principales de la administración central de la provincia de Mendoza. Esta decisión se fundamenta en que quienes accedieron a cargos electivos tuvieron que atravesar cierta competencia, y para ello, fue necesario que poseyeran determinados atributos, tales como el reconocimiento y la distinción al interior de un grupo de pares. Asimismo, se ha considerado importante ampliar el cuadro de análisis integrando en la muestra original a los ministros de las diferentes carteras administración pública provincial, a los efectos de disponer de una mirada de conjunto sobre el personal político. El fín último de la selección de este colectivo es examinar la estructuración de las redes político-administrativas a partir de los vínculos que se crean y recrean entre dirigentes políticos, funcionarios ministeriales y las burocracias estatales (Sawicki \& Mathiot 1999). En cuanto al recorte temporal, la investigación ha incorporado el personal de cuatro administraciones, una radical (1983-1987) y tres peronistas (1987-1999), para las que se halló información detallada y homogénea ${ }^{3}$.

La base nominativa fue construida a partir de una diversidad de fuentes documentales que provienen de los archivos del Congreso de la Nación Argentina, de la Legislatura de Mendoza y de la administración pública provincial. A esta pesquisa documental se ha adicionado información proveniente de la
${ }^{3}$ A partir de esa fecha, la Legislatura de Mendoza dejó de registrar datos relativos a los perfiles de los legisladores, lo que dificultó extender el periodo de análisis. 
prensa, a partir de la consulta de los diarios provinciales Los Andes, Mendoza, Hoy y Uno, y de diarios nacionales La Nación y Clarín. Finalmente, el trabajo se ha nutrido de un total de 40 entrevistas en profundidad, seleccionadas a partir de la técnica de bola de nieve (Pollak 2000). Estas entrevistas fueron realizadas a políticos que habían alcanzado los cargos que habían sido definidos en el corpus, guardando relación con la proporción de puestos analizados en la base de datos. Las entrevistas en profundidad permitieron cotejar la información de índole cuantitativa con la cualitativa, y así poder restituir las trayectorias individuales y de grupo.

Las trayectorias trazadas a partir de un conjunto de variables cuantitativas, como la edad, la composición por género, el nivel educativo y las profesiones de origen, colaboran en develar los canales de reclutamiento de las élites políticas a partir de los diferentes espacios sociales. Este análisis permite observar la manera en que se forjan las carreras políticas, dando cuenta de las ventajas u obstáculos en el ascenso a las posiciones jerárquicas. Con ello se buscar dar cuenta de las dificultades que ha atravesado el proceso de profesionalización de la actividad política en la Argentina de fines del siglo XX.

\section{Las carreras del personal político en democracia. El reclutamiento de acuerdo a la edad y la militancia partidaria}

${ }^{4}$ Esta mayoría que obtuvo el radicalismo se tradujo en 129 bancas en la Cámara de Diputados de la Nación y 18 senadurías. En cambio, el peronismo obtuvo 111 diputaciones nacionales y 21 senadurías. El esquema fue diferente en las provincias: el peronismo obtuvo doce gobernaciones provinciales, mientras que el radicalismo obtuvo tan solo 6. Cf. Persello (2007, p.289).

${ }^{5}$ El partido demócrata es una organización de carácter provincial y hunde sus raíces en viejo partido demócrata nacional, que integró la colación de gobierno durante el periodo conservador en los años 30. En Mendoza, alcanzaron la administración provincial durante la década de 1930 y también cuando se celebraron elecciones en los años 60 , en momentos en que el peronismo estaba proscripto.

${ }^{6}$ Excepcionalmente en 1983 se eligió la totalidad de la Cámara de Diputados de la Nación, debido al inicio del proceso democrático. Luego, la misma se renovó por mitades en elecciones que se llevaron a cabo cada dos años. En consecuencia, la provincia
El proceso democrático se inició en 1983 con el triunfo de la Unión Cívica Radical (UCR) tanto en el ámbito nacional como provincial. Luego de una intensa campaña electoral, la fórmula presidencial de Ricardo Alfonsín - Víctor Martínez se impuso por el $52 \%$ de los votos, frente al $40 \%$ que obtuvo la fórmula de Italo Lúder - Deolindo Bittel (Persello 2007, p.289) ${ }^{4}$. El peronismo había sido derrotado por primera vez en elecciones libres sin proscripciones. En la provincia de Mendoza, los resultados fueron también contundentes: el 47,1\% de los votos correspondieron al radicalismo, frente al 36,1\% del justicialismo y el $13 \%$ obtenido por el partido demócrata, que competía sólo en la provincia ${ }^{5}$. El saldo de la contienda electoral fue una mayor disposición de cargos para el partido radical, traducido en el envío de 6 diputados nacionales por Mendoza del conjunto de 10 que representan a la provincia ${ }^{6}$. También esto se reflejó en la Legislatura provincial, que de un total de 48 cargos que se disputaron para diputados provinciales obtuvo 25 frente a 18 del justicialismo y 5 del partido demócrata $^{7}$. Asimismo, de 38 cargos para senador provincial el radicalismo obtuvo 19, el justicialismo 15 y el partido demócrata $4^{8}$. Todo ello colaboró para que el radicalismo se consolidara en el poder, obteniendo importantes partidas de financiamiento público. La obtención de puestos favoreció la profesionalización de estos elencos dirigentes.

El gobernador electo de la provincia de Mendoza, Santiago F. Llaver, integró su gabinete ministerial y los principales peldaños de la administración pública siguiendo un criterio que había dominado el reclutamiento en el seno del partido radical: la antigüedad en la militancia partidaria9 ${ }^{9}$ Los ministros seleccionados describían un importante compromiso con el partido, y podían ser considerados militantes dentro de la agrupación. Los nombramientos incluyeron a representantes de las fracciones mayoritarias que integraban la organización: Renovación y Cambio y Causa Nacional ${ }^{10}$. Si bien la UCR había llegado al poder con un fuerte apoyo del sector de la Coordinadora vinculado a Franja Morada y a la militancia universitaria ${ }^{11}$, la juventud sólo logró el cargo de Director General de Escuelas, que quedó en manos de un joven abogado ${ }^{12}$. El resto del gabinete estaba integrado por personal que exhibía una experiencia más dilatada y tenía una trayectoria importante en el partido. El ministro de Gobierno, el abogado León Víctor Chade, pertenecía al círculo íntimo del gobernador electo: había sido socio en su estudio jurídico y militado en la 
de Mendoza debió seleccionar 10 diputados en las elecciones de 1983, y 5 en las contiendas consecutivas.

${ }^{7}$ La Cámara de Diputados provincial está integrada por 48 miembros que se renueva por mitades cada dos años.

${ }^{8}$ La Cámara de Senadores provincial cuenta con 38 miembros que se renuevan por mitades cada dos años.

${ }^{9}$ En investigaciones en torno a las prácticas políticas del partido radical se ha destacado el papel fundamental que tenía la afiliación partidaria para construir carreras políticas y la escasa participación de extrapartidarios en la constitución de los primeros gobiernos radicales (1916-1930). Cf. Ferrari (2008, pp.259-265).

${ }^{10}$ El Movimiento de Renovación y Cambio es una corriente interna del partido radical creada en junio de 1972, bajo el liderazgo de Raúl Alfonsín. Su objetivo era "remozar" el partido, para renovar su capacidad de movilización y organización. Cf. Persello (2007, p.239 y ss). Causa Nacional, de carácter territorial y provincial, fue creada en 1982 bajo el liderazgo del dirigente José Genoud.

${ }^{11}$ Franja Morada es una corriente de militancia estudiantil creada bajo el gobierno militar de la denominada "Revolución Argentina" - cuyo primer presidente fue el Gral.

Onganía (1966-1970) - y se convirtió en el brazo universitario de la juventud radical. Su nombre remite a una vieja denominación del reformismo universitario. Cfr. Altamirano (1987); Persello (2007).

${ }^{12}$ Hugo Duch había participado del grupo de profesionales que había colaborado con el sector de Renovación y Cambio. Duch, H. (9 de setiembre de 2009). Entrevista al Dr. Hugo Duch. Entrevistador: Autora.

${ }^{13}$ Los Andes, 13 de diciembre de 2013.

${ }^{14}$ Completaban la nómina de ministros el arquitecto Gerardo Andía, que fue designado ministro de Obras y Servicios Públicos, y el Dr. Rodolfo Montero, designado ministro de Bienestar Social. fracción de Renovación y Cambio desde su creación ${ }^{13}$. El ministro de Economía, el abogado Luis Ignacio Bobillo, era militante del sector de Causa y había sido asesor en temas económicos durante la presidencia de Arturo Illia (19631966). El ministro de Hacienda, Alberto Cyrlen Zabala, fue asesor del Ministro de Defensa del gobierno de Illia, Leopoldo Suarez ${ }^{14}$. Desde una mirada de conjunto, la fisonomía del gabinete ministerial respondía a criterios de selección claros: la mayoría eran abogados de profesión, habían realizado sus primeras experiencias durante la gestión del presidente Illia, por lo que llegaban a ocupar sus cargos ya con una trayectoria importante en la actividad política, y la militancia partidaria constituía un atributo fundamental para las posiciones que ocupaban. En algunos casos, estos criterios se adicionaban a los vinculados con redes amicales o familiares. La selección de quienes gobernaban ofrece indicios sobre algunas de las creencias que dominaron los primeros años del gobierno radical: el modelo era el ofrecido por el gobierno del presidente Illia, y el diagnóstico coincidía con el de aquella época (Persello 2007, p.290).

Si la imagen que arroja la primera composición ministerial destaca un reclutamiento de tipo "tradicional", es decir, el peso de la militancia partidaria para forjar una carrera política, otra es la percepción de lo ocurrido en las primeras cohortes que integraron la Legislatura provincial. La composición por grupos etáreos permite medir el grado de renovación de la dirigencia política y los inicios tempranos o tardíos en la actividad. A partir de ello se pueden hallar pautas para estimar los posibles pasos en las carreras políticas. El Gráfico 1 y el Gráfico 2 muestran las edades de diputados y senadores provinciales que integraron la Legislatura entre 1983 y 1999.

Desde una mirada de conjunto, y sin distinciones de partidos políticos, se observa que en las primeras elecciones de 1983 y 1985 la Legislatura fue integrada por una diversidad de grupos de edades. En efecto, la dispersión del universo es mayor al inicio del periodo democrático, que cuando éste adquiere cierta estabilidad. Este tipo de reclutamiento es tributario de la coyuntura particular que representó 1983, donde los dirigentes de edad avanzada tuvieron la posibilidad de continuar carreras políticas interrumpidas por sucesivos cortes institucionales. Los gobiernos autoritarios retrasaron el ingreso de ciertos dirigentes partidarios que tenían vocación política. La antigüedad en la militancia

Gráfico 1 - Composición de la Cámara de Diputados de Mendoza, según grupos etarios

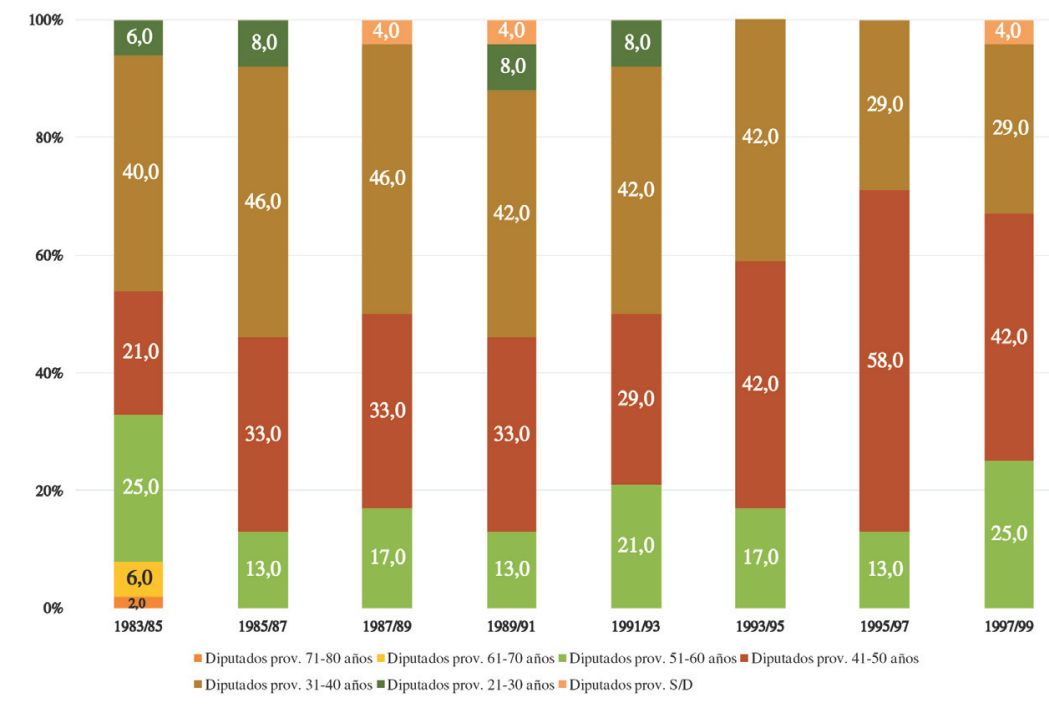

Fuente: Elaboración propia en base al Libro Matricular de la Honorable Cámara de Diputados de Mendoza. 
Gráfico 2 - Composición de la Cámara de Senadores de Mendoza, según grupos etarios

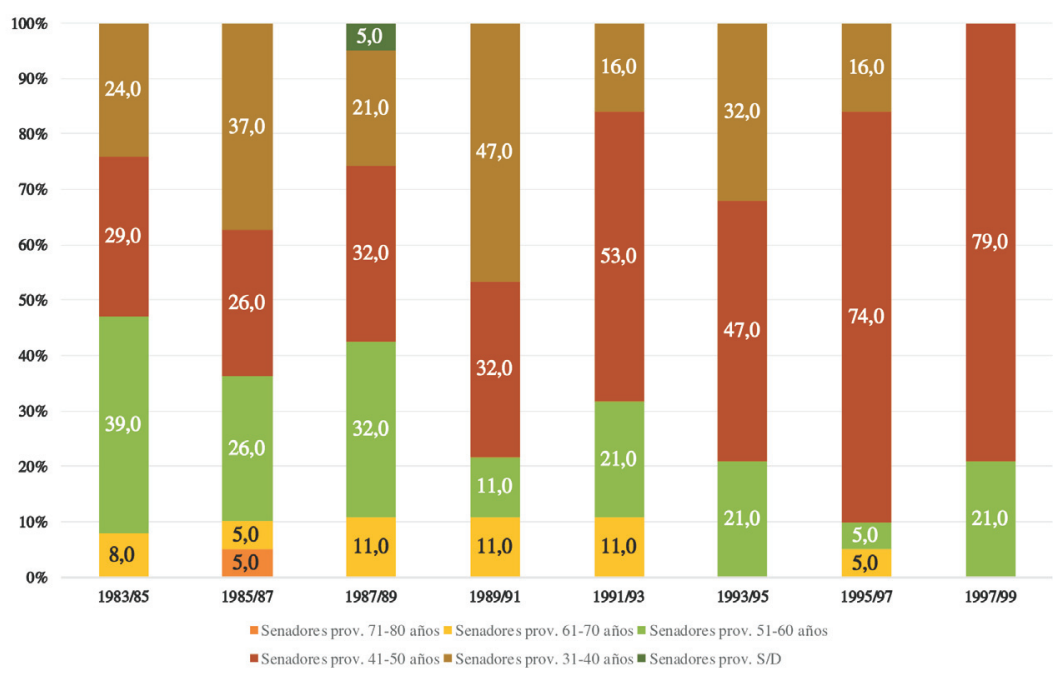

Fuente: Elaboración propia en base al Libro Matricular de la Honorable Cámara de Senadores de Mendoza.

partidaria fue un atributo que pesó a la hora de ser seleccionados como diputados y senadores provinciales, aunque esta condición no fue exclusiva. La importante presencia de cuadros jóvenes dentro del universo de la Legislatura exhibe también que la renovación de los elencos fue importante, y expresó la atracción que despertó la democracia en un conjunto de grupos, tales como profesionales universitarios, técnicos e intelectuales.

Sin embargo, desde una visión de largo plazo, la tendencia a la dispersión exhibida en la Legislatura provincial tiende a disminuir en las sucesivas cohortes luego de 1987, cuando el peronismo logró alcanzar la administración provincial y convertirse en mayoría parlamentaria. Los rangos de edad de los extremos, (entre los 21 y 30 años, entre los 61 y 70 años y entre los 71 y 80 años) tienden a desaparecer en las configuraciones de poder posteriores. La mayor densidad del rango entre 31 y 40 años de 1983 hasta 1991 y luego del rango entre 41 y 50 años, ilustran la instalación y consolidación de una generación de dirigentes que han hecho carrera en el seno de la Legislatura y entre los principales cargos de la administración pública.

Si se distingue el reclutamiento por edades de diputados y senadores provinciales de acuerdo a los partidos políticos, se observan algunas características distintivas entre las agrupaciones. La Tabla 1 expresa el promedio de edad de diputados y senadores provinciales por partido político:

Si el radicalismo en el gobierno priorizó colocar sus cuadros experimentados en los cargos ministeriales a partir de 1983, la imagen que arroja las primeras cohortes de diputados provinciales se aleja del reclutamiento de tipo "tradicional" basado en la antigüedad de la afiliación partidaria como criterio de selección. Tanto en 1983 como en 1985, dos elecciones donde el radicalismo batió a sus opositores, el promedio de edad de diputados y senadores es menor que la media general. La disposición de cargos en las administraciones nacional y provincial dejó lugar para la profesionalización de nuevas generaciones en las actividades parlamentarias. No obstante, la selección de candidatos radicales reflejaba también los cambios que había atravesado el partido, donde la Juventud, a través de la Coordinadora, había tenido un peso de importancia en el triunfo de Raúl Alfonsín y en los posteriores resultados electorales a través de su capacidad de movilización y su militancia en ámbitos específicos. Tal como han 
Tabla 1 - Promedio de edad de diputados y senadores provinciales por partido político (1983-1999)

\begin{tabular}{|c|c|c|c|c|c|c|c|c|c|}
\hline & & $1983 / 85$ & 1985/87 & $1987 / 89$ & 1989/91 & $1991 / 93$ & $1993 / 95$ & $1995 / 97$ & 1997/99 \\
\hline \multirow{5}{*}{$\begin{array}{l}\text { Diputados } \\
\text { prov. }\end{array}$} & Prom. General & 44,4 & 39,8 & 43,0 & 40,2 & 41,4 & 43,1 & 44,3 & 44,9 \\
\hline & $\mathrm{PJ}$ & 45,6 & 42,3 & 41,5 & 42,7 & 43,4 & 43,2 & 45,3 & 42,8 \\
\hline & UCR & 44,3 & 39,1 & 43,6 & 37,5 & 38,4 & 39,3 & 43,4 & 47,0 \\
\hline & PD & 40,8 & 38,3 & 47,3 & 40,2 & 40,0 & 49,8 & 45,3 & 44,0 \\
\hline & FREPASO & & & & & & & 42,0 & 44,0 \\
\hline \multirow{5}{*}{$\begin{array}{l}\text { Senadores } \\
\text { prov. }\end{array}$} & Prom. General & 48,6 & 47,6 & 48,6 & 43,7 & 48,6 & 43,7 & 44,7 & 46,7 \\
\hline & PJ & 48,1 & 49,5 & 48,9 & 40,3 & 50,9 & 44,3 & 42,8 & 46,0 \\
\hline & UCR & 47,9 & 46,9 & 47,3 & 46,8 & 42,2 & 42,8 & 49,5 & 46,0 \\
\hline & PD & 53,5 & 48,5 & 55,0 & 48,3 & 52,0 & 43,3 & 40,0 & 48,0 \\
\hline & FREPASO & & & & & & & 45,3 & \\
\hline
\end{tabular}

Fuente: Elaboración propia en base al Libro Matricular de la Legislatura de Mendoza.

expresado quienes participaban de la juventud radical en tiempos de la apertura democrática, los centros de estudiantes de las universidades y los grupos integrados por jóvenes constituyeron espacios importantes de reclutamiento para el partido. La pérdida de peso del radicalismo hacia 1987 y durante toda la década de 1990 debilitó el peso de estos espacios, aunque continuaron en la tarea de constituir una usina de dirigentes.

En el caso de los peronistas, el reclutamiento partidario es el que muestra una mayor dispersión entre los grupos etarios durante las primeras elecciones cercanas a 1983: a nivel provincial, el partido acudió tanto a cuadros de edad avanzada que mostraban una extendida experiencia en la actividad política como a integrantes jóvenes que tenían una escasa o nula práctica en las tareas legislativas. A modo de ejemplo, en 1986 convivía en el bloque peronista un diputado que llegó a su cargo con 71 años con uno de 32 años de edad. Esta dinámica de renovación parece aplacarse con la recurrencia regular a elecciones y la creciente estabilidad de los grupos políticos. La presencia de diputados y senadores de edad avanzada tiende a debilitarse, aunque no a extinguirse en la Legislatura provincial, lo que genera que en ciertas coyunturas electorales el promedio de edad de los justicialistas se coloque por encima del de los otros partidos políticos. Este dato resulta sugestivo porque ofrece indicios de las características del personal político que nutrió las administraciones justicialistas, familiarizadas con la Renovación peronista. Esta corriente interna dentro del partido creada como consecuencia de la derrota de 1983, que había propiciado el remozamiento de ideas, cuadros y estilos políticos frente a la "vieja" conducción en manos del sector sindical (Aboy Carlés 2001; Altamirano 2004; Ferrari \& Mellado 2016), incentivó la participación de jóvenes en política. La presencia (aunque minoritaria) de dirigentes de edad avanzada podría ser un indicio de la flexibilidad que ha mostrado el peronismo frente a cada coyuntura concreta. De cara al nuevo estilo político, el partido dio la posibilidad a los dirigentes de dilatada trayectoria de reconvertirse frente a nuevos liderazgos como el desplegado por el renovador José Octavio Bordón en el peronismo local (Mellado 2016b).

En cuanto a los dirigentes del partido demócrata, la Tabla 1 exhibe un promedio de edad diferenciado entre la Cámara de Diputados y la Cámara de Senadores provincial. Mientras que en la Cámara baja la media con la que ingresa un diputado demócrata es de 43,2 años, en la de Senadores es de 48,6 años, lo que indica un perfil específico para cada tarea legislativa. Esta brecha es aún más pronunciada en los primeros años de recuperación de la democracia. 
${ }^{15}$ Durante el periodo analizado, el partido demócrata alcanzó tan sólo dos diputaciones nacionales.

${ }^{16}$ El FREPASO fue una alianza de partidos constituida en 1994 e integrada principalmente por el Frente Grande de Carlos "Chacho" Álvarez y El PAIS (Política Abierta para la Integridad Social) de José Bordón. En las elecciones presidenciales de
Por ello, las estadísticas construidas tienden a poner en cuestión algunos presupuestos en torno al tipo de reclutamiento que describe el partido demócrata. Si bien se ha tendido a asociar al viejo partido conservador de Mendoza con una dirigencia estancada en el tiempo y con la importante presencia de cuadros de edad avanzada, el análisis de los perfiles de los diputados sugiere que la juventud demócrata alcanzó puestos de relevancia tras la apertura en 1983. Esta constatación adquiere mayor sentido si se trae a colación los magros resultados alcanzados por el PD durante el periodo democrático, llegando a ocupar sostenidamente el rol de segundo partido opositor, lo que evidencia que los dirigentes de menor experiencia habrían encabezado las listas de candidatos en algunas secciones electorales. Esta tendencia exhibida por un promedio de edad menor al del grupo en su conjunto, a excepción de las elecciones de 1987, 1993 y 1995, advierte que lo sucedido en 1983 no parece constituir un fenómeno fortuito, sino que la juventud demócrata continuó alcanzando espacios dentro de la Legislatura. Por otro lado, la incorporación de dirigentes con una larga experiencia en la Cámara de Senadores de Mendoza, y en menor medida en el Congreso nacional ${ }^{15}$, se debe a que estos espacios han constituido para los demócratas aquellos de mayor jerarquía posibles de alcanzar, de acuerdo con la performance del partido en el periodo democrático. Esta perspectiva ha sido diferente tanto para radicales como para peronistas, quienes no sólo han alcanzado el manejo de la administración provincial, sino que también, al pertenecer a partidos que disponen de una estructura nacional, han tenido la oportunidad de desarrollar carreras políticas más importantes y estables. La Cámara de Senadores de la Legislatura de Mendoza tanto para radicales como para justicialistas constituiría así un paso intermedio entre los cargos de menor y mayor jerarquía.

A pesar de que la evidencia empírica sobre el análisis de la variable etaria de Legislatura provincial exhibe la consolidación de una generación de dirigentes que realizó su trayectoria en la actividad parlamentaria provincial, no todo el personal político logró forjar una carrera exitosa, que exhibiera un ascenso desde el nivel provincial hacia el nacional. Inclusive, tan solo un selecto grupo logró la reelección en cargos legislativos provinciales, que, de acuerdo a la legislación vigente, no impide la consecución de mandatos. La Tabla 2 exhibe la relación entre los cargos registrados en la base de datos y las personas que los han desempeñado, discriminando quienes lograron alcanzar una carrera nacional y los que solo pudieron obtener cargos a nivel provincial.

Tal como exhibe la Tabla 2, el personal político en su conjunto muestra una alta tasa de renovación. Una gran mayoría exhibe una discontinuidad en la actividad, representado por el 73,9\% de personas que solo ha obtenido un cargo. Entre las 64 personas que se han desempeñado en dos cargos, el 89\% ha realizado una carrera en el nivel provincial. Como el universo que fue contemplado para este estudio está sobrerrepresentado por los legisladores provinciales, ese conjunto remite mayoritariamente a los miembros que han podido ser reelegidos en las cámaras provinciales. Finalmente, la tabla exhibe la fragmentación del campo político y la dificultad de realizar un cursus honorum en un sistema multinivel como el de la Argentina. Quienes alcanzan una carrera nacional se incluyen dentro del universo de 39 personas, que logran mantener cierta estabilidad en la actividad política. Entre ellas, 20 personas provenían del justicialismo, 15 del radicalismo, 3 del partido demócrata y 1 del FREPASO (Frente País Solidario) ${ }^{16}$, lo que exhibe la fuerte correlación entre el "éxito" de la carrera y los desempeños electorales de los partidos.

Esta situación provincial, de alta rotación de sus cuadros políticos encuentra parte de su explicación en las reglas institucionales vigentes que impiden la reelección del gobernador. A diferencia de la mayoría de las provincias argentinas que luego de 1983 reformaron sus constituciones provinciales habilitando la reelección de los gobernadores (Almaraz 2010), Mendoza no reformuló su 
Tabla 2 - Tasa de renovación del personal político de Mendoza y tipo de carrera política

\begin{tabular}{lccccccc}
\hline $\begin{array}{l}\text { Número de cargos } \\
\text { acumulados }\end{array}$ & $\begin{array}{c}\text { Número de } \\
\text { entradas }\end{array}$ & $\begin{array}{c}\text { Número de } \\
\text { personas }\end{array}$ & $\begin{array}{c}\text { Tasa de } \\
\text { renovación }\end{array}$ & $\begin{array}{c}\text { Carrera } \\
\text { Nacional }\end{array}$ & \% & $\begin{array}{c}\text { Carrera } \\
\text { provincial }\end{array}$ & $\%$ \\
\hline 5 cargos & 5 & 1 & 0,3 & & & 1 & \\
4 cargos & 20 & 5 & 1,3 & 3 & 60,0 & 2 & 40,0 \\
3 cargos & 99 & 33 & 8,4 & 18 & 54,5 & 15 & 45,5 \\
2 cargos & 128 & 64 & 16,2 & 7 & 10,9 & 57 & 89,1 \\
1 cargo & 292 & 292 & 73,9 & 11 & 3,8 & 282 & 96,6 \\
Total & 544 & 395 & 100,0 & 39 & 9,9 & 357 & 90,4 \\
\hline
\end{tabular}

Fuente: Elaboración propia en base al Libro Matricular de la Legislatura de Mendoza y la prensa.

1995 logró el segundo lugar, dejando en un tercer puesto al radicalismo. Luego, este partido integró la Alianza, que gobernó el país entre 1999 y 2001
Carta Magna. Por ello, su estructura de poder se diferencia de un conjunto de provincias argentinas, donde ciertas familias lograrían el dominio del Estado provincial, los medios de comunicación y el poder judicial. Esta última configuración de poder ofrece un escaso margen de maniobra a la oposición y repercute en la rotación del personal político y en las formas que adopta la democracia a escala subnacional (Behrend 2011).

\section{La profesionalización de las mujeres}

${ }^{17}$ María Inés Abrile de Vollmer había sido una militante peronista que había ingresado al partido a través de su militancia católica.

${ }^{18}$ Empresaria vinculada a una reconocida entidad financiera de Mendoza.
Una de las variables claves para comprender el reclutamiento de las élites políticas ha estado relacionada con el género, ya que colabora en iluminar las condiciones para ingresar a la actividad política de forma profesional. En la primera configuración de ministerios del gobierno radical en 1983, no hubo presencia de mujeres. Con el triunfo del peronismo en las elecciones de 1987, que retuvo la administración provincial por tres periodos consecutivos (19871999), nuevos criterios de selección se adicionaron. El justicialismo practicó el reclutamiento por "especialización por funciones", que llevó a convocar a un conjunto de extrapartidarios que no necesariamente se habían afiliado formalmente al partido peronista. Sin embargo, estos elencos habían participado informalmente de los espacios de socialización donde el partido reclutó a sus dirigentes (Mellado 2016b). El reclutamiento por "especialización de funciones" también se observó por medio de la diversidad de profesionales que integraron los cargos ministeriales. Es en esta coyuntura ofrecida por la alternancia de gobierno en 1987 que las mujeres comenzaron a ingresar en altos cargos de gestión pública. Durante la administración del justicialista José O. Bordón (1987-1991) se designó a María Inés Abrile de Vollmer como Ministra de Educación ${ }^{17}$. Por su parte, el gobernador Rodolfo Gabrielli (1991-1995) nombró a Elvira Castro para desempeñarse en el ministerio de Cooperación y Acción Solidaria y el gobernador Arturo Lafalla (1995-1999) integró en su gabinete a Ana María Mosso de Mortarotti para ocupar la cartera de economía ${ }^{18}$.

Desde una mirada de conjunto, la evidencia empírica exhibe que los cargos ministeriales han sido ocupados predominantemente por varones, y que la participación femenina se circunscribe esporádicamente a ciertas áreas como educación y desarrollo social. Es a partir de la segunda mitad de la década de 1990 que una mujer ocupó un cargo vinculado a tareas relacionadas principalmente con la actividad masculina, como es la economía y la hacienda.

Una visión de conjunto similar surge del análisis de la composición por género de la Legislatura provincial y de los diputados y senadores nacionales enviados por Mendoza al Congreso nacional entre 1983 y 1999. La Tabla 3 exhibe la participación de las mujeres en las cámaras legislativas provinciales: 
Tabla 3 - Participación de las mujeres en la Legislatura de Mendoza

\begin{tabular}{|c|c|c|c|c|c|c|c|c|c|c|}
\hline & \multicolumn{5}{|c|}{ Diputados provinciales } & \multicolumn{5}{|c|}{ Senadores provinciales } \\
\hline & Mujeres & $\%$ & Varones & $\%$ & Total & Mujeres & $\%$ & Varones & $\%$ & Total \\
\hline $1983 / 85$ & 3 & 6,3 & 45 & 93,8 & 48 & 2 & 5,3 & 36 & 94,7 & 38 \\
\hline $1985 / 87$ & 0 & 0,0 & 24 & 100,0 & 24 & 0 & 0,0 & 19 & 100,0 & 19 \\
\hline $1987 / 89$ & 1 & 4,2 & 23 & 95,8 & 24 & 0 & 0,0 & 19 & 100,0 & 19 \\
\hline 1989/91 & 1 & 4,2 & 23 & 95,8 & 24 & 1 & 5,3 & 18 & 94,7 & 19 \\
\hline $1991 / 93$ & 2 & 8,3 & 22 & 91,7 & 24 & 1 & 5,3 & 18 & 94,7 & 19 \\
\hline $1993 / 95$ & 5 & 20,8 & 19 & 79,2 & 24 & 4 & 21,1 & 15 & 78,9 & 19 \\
\hline $1995 / 97$ & 5 & 20,8 & 19 & 79,2 & 24 & 2 & 10,5 & 17 & 89,5 & 19 \\
\hline $1997 / 99$ & 5 & 20,8 & 19 & 79,2 & 24 & 3 & 15,8 & 16 & 84,2 & 19 \\
\hline
\end{tabular}

Fuente: Elaboración propia en base al Libro Matricular de la Legislatura de Mendoza.

${ }^{19}$ En este porcentaje no se ha contabilizado la diputación de Elia Ana Bianchi de Zizzias en reemplazo de Alfredo Mosso, quien renunció a su diputación nacional el 13/08/86 para ocupar la Secretaría de Defensa de la Nación.

${ }^{20}$ Hasta 1994, los senadores nacionales eran elegidos por las Legislaturas provinciales y cada provincia enviaba dos miembros. Con la reforma constitucional de 1994, cada provincia envía tres senadores, los cuales son elegidos por voto directo. La Cámara de Senadores de la Nación se renueva por tercios cada dos años.

${ }^{21}$ Ley $5.888 / 92$.

${ }^{22}$ Es un promedio de las elecciones de 1983 a 1991. Cf. Marx, Borner \& Caminotti (2007, p.60).
Tal como se observa, la participación de las mujeres en la Legislatura de Mendoza ha sido minoritaria. En la Cámara de Diputados de la provincia, de un total de 216 cargos disputados entre 1983 y 1997, las mujeres obtuvieron sólo 22 de ellos, alcanzando una representación del 10,1\%. La Cámara de Senadores de la provincia exhibe una imagen similar, aunque levemente más desigual. De 171 cargos que se disputaron, las mujeres obtuvieron sólo 13, alcanzando el $7,6 \%$ de la representación. Sumando la representación de ambas cámaras, las mujeres ocuparon el 9\% de los cargos disponibles. Esta situación no parece revertirse en cargos de mayor jerarquía como en diputaciones y senadurías nacionales. Durante el periodo analizado se pusieron en juego 40 cargos a diputados nacionales, y las mujeres conquistaron un solo cargo, alcanzando el $2,5 \%$ de la representación ${ }^{19}$. La presencia de senadoras nacionales es también reducida: tan sólo Margarita Malharro de Torres, dirigente de la UCR vinculada al sector de Renovación y Cambio fue propuesta por la Legislatura provincial para desempeñarse como senadora nacional. Desde la reforma de la Constitución en 1994 y hasta 1999, no se han presentado casos en que mujeres hayan sido elegidas senadoras por Mendoza ${ }^{20}$.

Sin embargo, un importante incremento de participación se produjo a partir de las elecciones legislativas de 1993. Este aumento es tributario de una modificación de las leyes electorales, que tuvo un impacto sobre la práctica de los partidos políticos. La ley $\mathrm{N}^{\circ}$ 24012/9110 - conocida como Ley de Cupo tuvo como objetivo aumentar la participación de las mujeres en las cámaras legislativas al obligar a que cada uno de los partidos políticos integre sus listas de candidatos al menos con un 30\% de mujeres ${ }^{21}$. La legislación de Mendoza adoptó ese mismo sistema de cuotas. Tal como lo manifiestan los gráficos, la ley de cupos tuvo en parte el efecto positivo buscado: la presencia de mujeres se incrementó notoriamente si se compara las elecciones entre 1983 y 1991 con las de 1993: la representación femenina en la Cámara de Senadores provincial pasó de un 3,5\% ${ }^{22}$ a un $21 \%$, y en la Cámara de Diputados provincial de un $4,8 \%$ a un $20,8 \%$. Cabe agregar que el porcentaje de representación femenina en la Legislatura entre 1983 y 1991 es similar al desplegado en el Congreso de la Nación, entre un 3 y 6\% (Marx et al., 2007), lo que implica que, en escalas más bajas de poder, las mujeres exhibían las mismas dificultades de acceso a puestos jerárquicos. Esta tendencia cayó levemente en las elecciones de 1995 hasta alcanzar un $10,5 \%$ para la Cámara de Senadores y se mantuvo estable para diputados.

Si bien la ley de Cupo logró asegurar una mayor presencia femenina, no va de suyo que esta reglamentación haya podido modificar las prácticas políticas y 
Tabla 4 - Tasa de renovación de las mujeres y tipo de carrera política

\begin{tabular}{lccccccc}
\hline $\begin{array}{l}\text { Número de cargos } \\
\text { acumulados }\end{array}$ & $\begin{array}{c}\text { Número de } \\
\text { entradas }\end{array}$ & $\begin{array}{c}\text { Número de } \\
\text { personas }\end{array}$ & $\begin{array}{c}\text { Tasa de } \\
\text { renovación }\end{array}$ & $\begin{array}{c}\text { Carrera } \\
\text { Nacional }\end{array}$ & $\%$ & $\begin{array}{c}\text { Carrera } \\
\text { provincial }\end{array}$ & $\%$ \\
\hline 3 cargos & 3 & 1 & 2,6 & & 0,0 & 1 & 100,0 \\
2 cargos & 6 & 3 & 7,7 & 2 & 66,7 & 1 & 33,3 \\
1 cargo & 35 & 35 & 89,7 & 1 & 2,9 & 34 & 97,1 \\
Total & 44 & 39 & 100,0 & 3 & 7,7 & 36 & 92,3 \\
\hline
\end{tabular}

Fuente: Elaboración propia en base al Libro Matricular de la Legislatura de Mendoza y la prensa.

${ }^{23}$ Este rol minoritario, derivado de la subordinación de las mujeres a la hegemonía patriarcal, al decir de Dora Barrancos, no se traduce en una ausencia de participación del espacio público. Cf Barrancos 2002; 2007; 2009

${ }^{24}$ La categoría de prestigio de las comisiones legislativas ha sido construida a partir de las entrevistas en profundidad, por ello resulta una categoría "nativa" de los propios entrevistados. el consecuente rol minoritario que han tenido tradicionalmente las mujeres en el juego político ${ }^{23}$. En la mayoría de los casos, las mujeres han sido incluidas en los espacios menos visibles o relevantes de las listas de candidatos, recortando sus chances reales de participación. El ingreso de diputadas/senadoras suplentes tras la renuncia de los representantes emplazados en las primeras líneas constituye un indicio de estas prácticas.

Así, las mujeres han sido incorporadas bajo la premisa de dar a la actividad política parlamentaria una visión menos masculina, con el objeto de moralizar la política, conservando una posición relativa de menor jerarquía al conformar las listas de candidatos y los lugares de relevancia en los espacios de poder. La participación de las mujeres en comisiones parlamentarias menos "prestigiosas" que en la que participan sus pares varones atestiguan también este tipo de prácticas ${ }^{24}$.

Las dificultades para alcanzar puestos jerárquicos siendo mujer también se exhibe en el desempeño de sus carreras políticas. La Tabla 4 muestra la tasa de renovación de las mujeres, que mide sus posibilidades de ser reelectas en sus cargos o de pasar a otro cargo de mayor o igual jerarquía.

La tabla resulta contundente de los obstáculos que adosa la categoría de género para desempeñarse en la actividad política, haciendo visible lo que los especialistas han llamado el "ceiling glass" [techo de cristal]. Esta expresión alude a los diversos mecanismos sociales que dificultan el acceso de las mujeres a los cargos de alta jerarquía (Luci 2016). Mientras que la tasa de renovación para el conjunto, sin distinción de género, alcanza el $73,9 \%$, si se contabilizan solo las mujeres, esta tasa asciende al $89,7 \%$. Inclusive, la poca presencia de mujeres que hayan logrado una carrera de alcance nacional también muestra las trabas asociadas a la condición de género. Esta mayor dificultad está asociada, de acuerdo con las entrevistas en profundad, en la continua exigencia de la actividad política, que requiere una dedicación full-time, lo que dificulta la armonización con las tareas del hogar y el cuidado de la descendencia.

En cuanto al reclutamiento de mujeres, los partidos políticos han desempeñado diferentes roles en referencia a su incorporación. La Tabla 5 muestra la distribución de diputadas y senadoras provinciales por partidos políticos.

Estas particularidades en el reclutamiento del personal femenino pueden ser atribuidas a las diferencias culturales e identitarias de las organizaciones y de sus estrategias de conquista del electorado. De la totalidad de las mujeres que han ingresado a la Legislatura provincial durante el periodo analizado, el 84,6\% de las senadoras y el $77,2 \%$ de las diputadas lo hicieron a través del partido justicialista. Este dato viene a reforzar la imagen que ofrece el reclutamiento de los cargos ministeriales: la presencia de ministras provinciales mujeres se ha llevado a cabo sólo a través de las administraciones justicialistas entre 1983 y 1999. Este tipo de práctica distintiva del justicialismo hunde sus raíces en su tradición partidaria. Desde la fundación del partido peronista femenino en 1949, 
Tabla 5 - Distribución de diputados y senadores provinciales por género y partido político (1983-1999)

\begin{tabular}{|c|c|c|c|c|c|c|c|c|c|c|}
\hline & & & $1983 / 85$ & $1985 / 87$ & $1987 / 89$ & $1989 / 91$ & $1991 / 93$ & $1993 / 95$ & $1995 / 97$ & $1997 / 99$ \\
\hline \multirow{16}{*}{$\begin{array}{l}\text { Diputados } \\
\text { prov. }\end{array}$} & PJ & M & 3 & 0 & 1 & 1 & 2 & 4 & 4 & 2 \\
\hline & & $\mathrm{V}$ & 15 & 6 & 11 & 10 & 13 & 10 & 8 & 7 \\
\hline & & $\mathrm{T}$ & 18 & 6 & 12 & 11 & 15 & 14 & 12 & 9 \\
\hline & & $\mathrm{M} / \mathrm{V}$ & 20,0 & 0,0 & 9,1 & 10,0 & 15,4 & 40,0 & 50,0 & 28,6 \\
\hline & UCR & M & 0 & 0 & 0 & 0 & 0 & 1 & 0 & 0 \\
\hline & & V & 25 & 14 & 9 & 8 & 8 & 5 & 5 & 5 \\
\hline & & $\mathrm{T}$ & 25 & 14 & 9 & 8 & 8 & 6 & 5 & 5 \\
\hline & & $\mathrm{M} / \mathrm{V}$ & 0,0 & 0,0 & 0,0 & 0,0 & 0,0 & 20,0 & 0,0 & 0,0 \\
\hline & PD & M & 0 & 0 & 0 & 0 & 0 & 0 & 1 & 2 \\
\hline & & $\mathrm{V}$ & 5 & 4 & 3 & 5 & 1 & 4 & 3 & 7 \\
\hline & & $\mathrm{T}$ & 5 & 4 & 3 & 5 & 1 & 4 & 3 & 9 \\
\hline & & $\mathrm{M} / \mathrm{V}$ & 0,0 & 0,0 & 0,0 & 0,0 & 0,0 & 0,0 & 33,3 & 28,6 \\
\hline & FREPASO & $\mathrm{M}$ & & & & & & & 0 & 1 \\
\hline & & V & & & & & & & 4 & 0 \\
\hline & & $\mathrm{T}$ & & & & & & & 4 & 1 \\
\hline & & $\mathrm{M} / \mathrm{V}$ & & & & & & & 0,0 & \\
\hline \multirow{16}{*}{$\begin{array}{l}\text { Senadores } \\
\text { prov. }\end{array}$} & PJ & $\mathrm{M}$ & 2 & 0 & 0 & 1 & 1 & 4 & 1 & 2 \\
\hline & & V & 13 & 4 & 10 & 9 & 12 & 6 & 8 & 5 \\
\hline & & $\mathrm{T}$ & 15 & 4 & 10 & 10 & 13 & 10 & 9 & 7 \\
\hline & & $\mathrm{M} / \mathrm{V}$ & 15,4 & 0,0 & 0,0 & 11,1 & 8,3 & 66,7 & 12,5 & 40,0 \\
\hline & UCR & M & 0 & 0 & 0 & 0 & 0 & 0 & 0 & 0 \\
\hline & & $\mathrm{V}$ & 19 & 13 & 8 & 5 & 5 & 5 & 4 & 5 \\
\hline & & $\mathrm{T}$ & 19 & 13 & 8 & 5 & 5 & 5 & 4 & 5 \\
\hline & & $\mathrm{M} / \mathrm{V}$ & 0,0 & 0,0 & 0,0 & 0,0 & 0,0 & 0,0 & 0,0 & \\
\hline & PD & M & 0 & 0 & 0 & 0 & 0 & 0 & 0 & 1 \\
\hline & & V & 4 & 2 & 1 & 4 & 1 & 4 & 3 & 6 \\
\hline & & $\mathrm{T}$ & 4 & 2 & 1 & 4 & 1 & 4 & 3 & 7 \\
\hline & & $\mathrm{M} / \mathrm{V}$ & 0,0 & 0,0 & 0,0 & 0,0 & 0,0 & 0,0 & 0,0 & 16,7 \\
\hline & FREPASO & $\mathrm{M}$ & & & & & & & 1 & 0 \\
\hline & & V & & & & & & & 2 & 0 \\
\hline & & $\mathrm{T}$ & & & & & & & 3 & 0 \\
\hline & & $\mathrm{M} / \mathrm{V}$ & & & & & & & 50 & 0 \\
\hline
\end{tabular}

Fuente: Elaboración propia en base al Libro Matricular de la Legislatura de Mendoza.

la organización aseguraba un tercio del total de las candidaturas a las mujeres, lo que resultó una experiencia clave para el personal político femenino, proveniente mayoritariamente de sectores populares (Marx et al., 2007, p.51; Barry 2009). Si bien el partido justicialista no logró reeditar los niveles de participación alcanzados en 1952 - donde el personal femenino representaba el 15,4\% en la Cámara de Diputados de la Nación y el 20\% de integrantes del Senado Nacional como producto del ascendente liderazgo de Eva Perón, (Marx et al.,

${ }^{25}$ La participación lograda por las mujeres en el Congreso nacional de 1952 no se 2007, p.51) ${ }^{25}$ - y dejó de utilizar el sistema de representación en ramas, la participación femenina forjó una tradición de reclutamiento perdurable en el tiempo y visible en los diferentes niveles. Desde 1983, las mujeres han estado 
traducía en un importante nivel de decisión, sino que ha sido interpretado como el espacio generado por el poder informal de Eva Perón más que por el propio poder de movilización de las mujeres. Cf. Peláez y Valobra (2004).

${ }^{26}$ Cf. Carta Orgánica del partido demócrata y Carta Orgánica de la UCR, Provincia de Mendoza. lejos de alcanzar el tercio de los cargos conquistados por el peronismo, tal como atribuía la separación en ramas, pero han seguido teniendo representación dentro de la diversidad sociocultural y política que ha integrado el partido.

El reclutamiento de mujeres dentro del peronismo contrasta con el del resto de los partidos políticos: el partido radical ha colocado sólo una mujer como diputada provincial en las elecciones de 1993, el FREPASO una senadora en las elecciones de 1995 y el partido demócrata una senadora en 1997. Si bien los espacios de representación tanto del partido radical como demócrata se han visto reducidos por los magros resultados electorales que obtuvieron durante la década de 1990, la menor participación de las mujeres en las tareas legislativas y partidarias parece responder a una particular concepción de poder dentro de las organizaciones. No obstante, este rasgo parece ir cambiando paulatinamente en los últimos años: tanto el partido radical como el partido demócrata han incorporado el sistema de cuotas femenino para los cargos partidarios de conducción en franca alusión al proceso de ampliación del ámbito de aplicación de los cupos legales ${ }^{26}$.

En cuanto a las tareas específicas que desempeñan las mujeres en las cámaras legislativas y en los espacios de decisión, las mismas se relacionan con sus formaciones de origen. Si bien el 70,3\% de ellas han alcanzado el nivel universitario o terciario, mostrando una mayor homogeneidad en cuanto al perfil socioprofesional que la descripta por los hombres, sus profesiones previas al ingreso en política se encuentran ligadas con la educación. En efecto, de un total de 19 mujeres diputadas, senadoras y ministras provinciales para las que se han obtenido datos de su perfil profesional, el 63,15\% son docentes mientras que el 10,5\% son escribanas y el 10,5\% psicólogas. Esta importante porción de docentes en cuanto a la profesión de origen es un tipo de perfil que se sostiene en el tiempo y responde a las características que ha descripto el sector educativo en la Argentina, el cual se ha nutrido principalmente de mujeres.

Las experiencias profesionales previas han llevado a que las mujeres integren, en su mayoría, las comisiones legislativas de educación y desarrollo social. La sobrerrepresentación de mujeres en estas comisiones ilustra también una desigual distribución del poder al interior de ellas. En efecto, cada comisión tiene un peso específico particular, no sólo por el tipo de tareas que se realiza sino también por el tipo de relaciones sociales que genera respecto del conjunto del entorno político y económico. Por ello, participar o dirigir una comisión, especialmente aquellas que tienen más prestigio, como economía o hacienda, colabora para la construcción de carreras políticas exitosas.

Finalmente, en cuanto a los orígenes sociales, las mujeres describen las mismas características que los hombres y, por lo tanto, reproducen la fisonomía del campo político (Bourdieu 1990). Por ello, el caso estudiado viene a corroborar que la progresiva inclusión de las mujeres no implicaría un acercamiento en la brecha entre quienes son profesionales de la política y quienes no lo son (Sineau 2001, p.210). En suma, la actividad política es predominantemente una actividad de varones y las mujeres han desempeñado un rol minoritario en el periodo estudiado. Sus dedicaciones a tareas de menor prestigio dentro de los espacios de poder dan cuenta de este "estatus minoritario". Sin embargo, esta constatación no debe ensombrecer el rol de las mujeres en el armado de redes políticas, como en el asesoramiento técnico o el papel que han jugado como intermediarias en las redes de sociabilidad provincianas (Mellado 2016b). Como lo ha sugerido una importante literatura, el papel de las mujeres en el mercado matrimonial, los matrimonios políticos, el trabajo de movilización de lazos familiares para posibilitar las alianzas familiares resulta central en la construcción de poder político, aún en sociedades contemporáneas (Canedo 2002; Bragoni 1999; Ferrari 2008). Las mujeres realizan así un trabajo “invisi- 
ble" y cotidiano que colabora en la emergencia de liderazgos masculinos (Mellado 2016b).

\section{Los perfiles de acuerdo con el grado de instrucción formal}

El nivel educativo alcanzado constituye otro indicador valioso para examinar los perfiles de diputados, senadores, ministros y personal político en general. El Gráfico 3 exhibe los niveles educativos tanto de diputados y senadores provinciales y nacionales como de ministros de gobierno en el periodo 19831999.

La imagen que arroja el gráfico sugiere el alto nivel educativo que alcanzaron tanto los senadores y diputados que integraron el Congreso nacional como los ministros de la administración provincial. Estas cifras permiten sugerir que los cargos vinculados con posiciones jerárquicas, es decir, aquellos ligados a quienes logran integrar la dirigencia nacional, son ocupados por aquellos que poseen un título universitario y han logrado cierta posición social. Aunque este fenómeno puede ser tributario de una reproducción de posiciones ya adquiridas en el seno familiar y relacional o de una movilidad social ascendente, la composición por nivel educativo apunta a mostrar el perfil social diferenciado, alcanzado o ya adquirido, para ser parte de la dirigencia nacional o de cumplir funciones técnicas.

Por otro lado, el alto porcentaje de ministros con título universitario y con una fuerte especialización en las funciones sugiere también la decisión de los líderes partidarios de seleccionar para los principales puestos de la administración pública, personal especializado para esas tareas. Si bien el conjunto del grupo de ministros exhibe una fuerte correlación entre nivel educativo y adquisición del cargo, la especialización de los ministros es más nítida en las administraciones justicialistas que en la radical, al vincular título universitario con tarea específica, lo que corrobora nuevamente el predominio del tipo de reclutamiento por "especialización de funciones" a partir de 1987. En la mayoría de los casos, los ministros integraron los cuerpos de profesionales que organizaron los programas y las plataformas con las que alcanzaron el poder los partidos políticos. En contraste, la Legislatura provincial emerge como el espacio intermedio en donde confluyen tanto quienes poseen títulos universitarios como quienes no los poseen. Si bien la tendencia de quienes no poseen

Gráfico 3 - Nivel educativo del personal político de Mendoza (1983-1999) ${ }^{\mathrm{I}}$

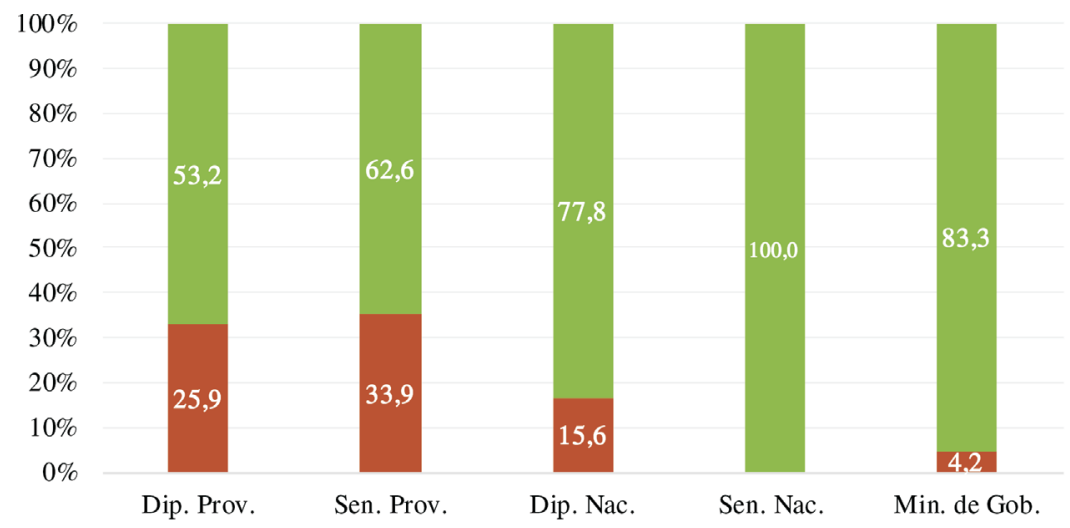

Quienes possen título de educación superior $\square$ Quienes No poseen título de educación superior

Fuente: Elaboración propia en base al Libro Matricular de la Legislatura de Mendoza y la prensa.

${ }^{\mathrm{I}}$ Las diferencias en relación a $100 \%$ responden a los datos no informados. 
título parece debilitarse en las últimas cohortes de senadores y diputados provinciales, una porción de cargos parece estar destinada a aquellos que, si bien no tienen conocimientos específicos validados institucionalmente, "controlan" cierto territorio o son reconocidos en sus lugares de origen. En efecto, la Legislatura constituye un punto de partida para quienes desarrollan carreras nacionales y un punto de llegada para quienes manejan ciertos vínculos territoriales y redes de adherentes. La Legislatura provincial representaría así el punto de intersección o confluencia de un conjunto de carreras políticas diversas.

Respecto del grado de instrucción formal alcanzado por partido político, no hay diferencias sustanciales entre los perfiles del personal político que integra las diferentes organizaciones partidarias. Mientras que la especialización de los ministros es similar en los gobiernos de diferente color político, el nivel de instrucción alcanzado entre peronistas, radicales y demócratas en las cámaras legislativas provinciales alcanza porcentajes similares. Los senadores provinciales que poseen títulos de educación superior dentro del radicalismo representan el 57,81\%, los justicialistas alcanzan el 63,64\% y los demócratas el 66,67\%, lo que contrasta con anteriores cohortes legislativas provinciales que muestran un perfil diferenciado entre radicales y demócratas, por un lado, y peronistas y socialistas, por otro lado (Strout 1968; Mellado 2015, p.170). Esta homogeneización y consecuente cambio de perfil es tributario de las transformaciones al interior del partido justicialista a partir de 1983. Las mutaciones que trajo aparejada la Renovación peronista como corriente interna pueden ser observadas en la oclusión de ciertos canales de reclutamiento, especialmente aquellos que movilizaban a dirigentes que provenían de sectores populares, como sindicalistas y obreros (Gutiérrez 2003). La visión, proyección y éxito de ciertos liderazgos, como es el caso del renovador José Bordón en Mendoza, aportó elementos diferenciales respecto a esta particular vía de entrada en política. Su afán de exhibir un nuevo rostro al interior del partido justicialista y el peso que logró en la organización para impulsar y vetar candidaturas influyó en el cambio de perfil de los dirigentes a nivel provincial y local, abriendo u obturando posibilidades de ascenso (Mellado 2016b).

A pesar de que en la etapa democrática se ha producido una masificación de los títulos universitarios, la constatación de que una gran porción de población en la actualidad no logra terminar la universidad, permite afirmar que el egreso de una institución de la educación superior sigue constituyendo un valor de distinción. En este sentido, la estabilidad democrática parece confirmar una tendencia internacional que se exhibe en los parlamentos y en los altos cargos de decisión política de las distintas democracias occidentales del mundo: el aumento de los porcentajes de parlamentarios y personal político con credenciales universitarias.

\section{Ocupaciones y actividades laborales previas al ingreso a la política}

Si el nivel educativo permite describir a quienes han tenido acceso a los principales puestos de decisión política, el estudio de las actividades laborales - y de obtención de ingresos - previas a la entrada en política completan este análisis y nos acercan hacia los espacios de formación y socialización de cuadros. En efecto, la exploración de las ocupaciones anteriores al ingreso al campo político revela las variaciones observables en el reclutamiento del personal. Es decir, a través de ellas se pondera qué grupos han permanecido "constantes" entre los elencos gobernantes y cuáles han sido las vías de acceso al espacio político. El Gráfico 4 muestra las ocupaciones previas de ministros de las cuatro administraciones:

En cuanto al reclutamiento profesional en las carteras ministeriales, el gráfico exhibe que los abogados han dominado durante la administración radi- 
Gráfico 4 - Profesiones y actividades previas de los ministros por administración (1983-1999)

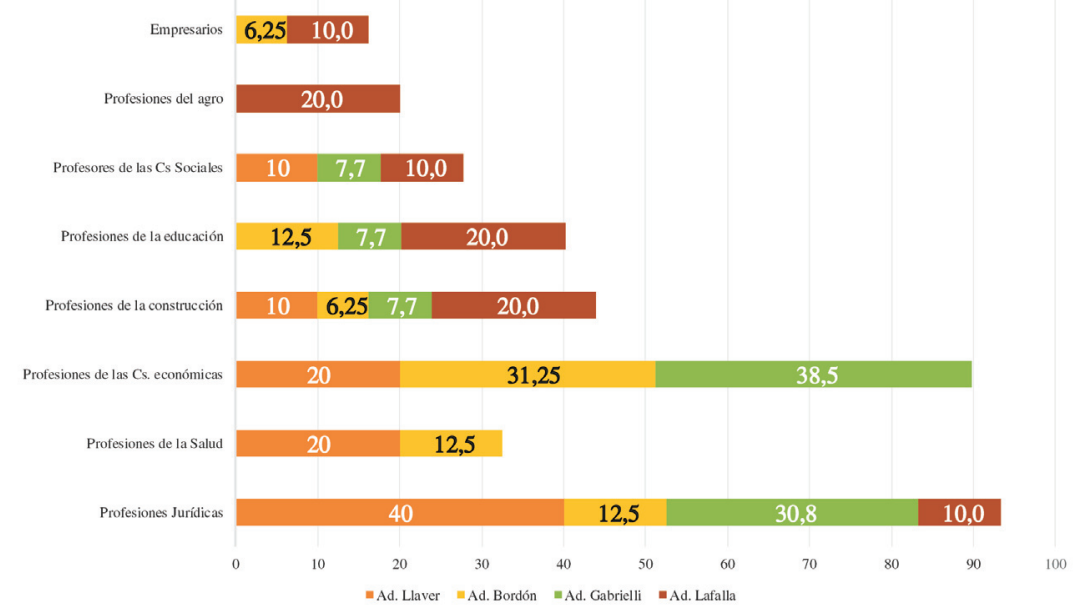

Fuente: Elaboración propia en base al Libro Matricular de la Legislatura de Mendoza y la prensa.

cal, inclusive en aquellos cargos que requerían una mayor especialización técnica - como en el ministerio de economía o en el ministerio de educación -. Por el contrario, durante los gobiernos justicialistas se percibe un reclutamiento más amplio de acuerdo con las categorías socioprofesionales, y un mayor ingreso de cuadros provenientes de las profesiones de ciencias económicas, aunque los abogados siguen poseyendo una posición privilegiada. Este paulatino cambio sugiere que, durante sus primeros tramos, la experiencia democrática abierta en 1983 no parece haber alterado algunas pautas que describía la política argentina en torno a los canales de reclutamiento de su personal. Tal como han resaltado los estudios pioneros en torno a los elencos dirigentes, los abogados son aquellos profesionales más proclives a "vivir de la política" en el largo plazo (De Imaz 1964, p.26; Canelo 2011, p.143; Buchbinder 2012, p.116).

Si de acuerdo con la variable referente al nivel educativo se observaba una mayor porción de egresados universitarios entre los ministros y un menor porcentaje entre quienes integraban la Legislatura, el análisis de las actividades previas colabora en trazar el perfil de diputados y senadores provinciales y a dilucidar qué ocupaciones son más proclives para forjar una carrera política. El Gráfico 5 describe las ocupaciones y actividades previas de diputados y senadores provinciales entre 1983 y 1999:

Una primera aproximación muestra una importante heterogeneidad de ocupaciones al interior del colectivo: el conjunto de diputados y senadores provinciales presenta un amplio abanico de actividades declaradas como actividad previa $^{27}$. Una importante porción registra una alta especialización - abogados, escribanos, profesiones ligadas a las ciencias económicas - aunque también se halla en el conjunto del personal un reclutamiento más amplio en ocupaciones que no han requerido una especialización universitaria - comerciantes y obreros calificados.

No obstante, a pesar de esta heterogeneidad, algunos grupos profesionales con título universitario están más relacionados con la actividad política, como lo puede sugerir el importante volumen de abogados. En el caso de la Legislatura Provincial, 40 puestos para senador de un total de $171(23,4 \%)$ y 49 para diputados de un total de $216(22,7 \%)$ fueron ocupados por abogados. Esta 
Gráfico 5 - Distribución de profesiones y actividades previas de diputados y senadores provinciales (1983-1999)

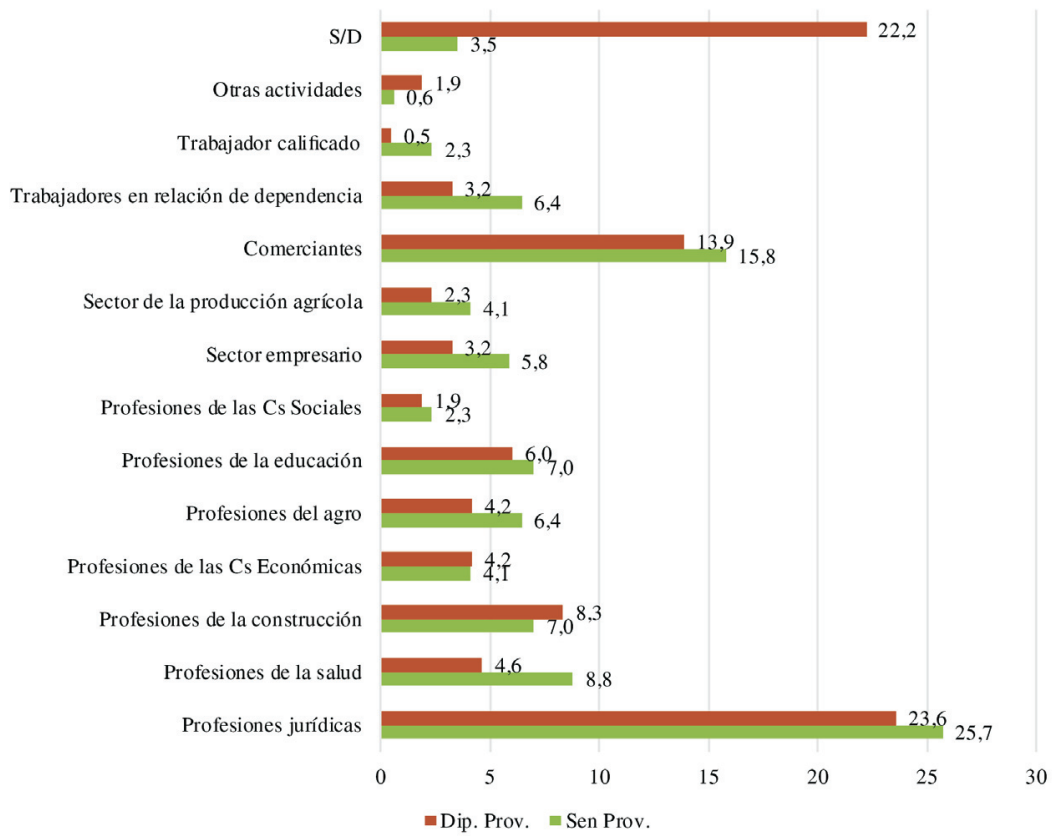

Fuente: Elaboración propia en base al Libro Matricular de la Legislatura de Mendoza y la prensa.

evidencia sugiere que poseer este título en la Argentina constituye una vía de entrada privilegiada para el ingreso en el campo de la política. En efecto, la profesión de abogado constituye un capital para el desempeño legislativo y profesional en la actividad. Asimismo, este título ha ofrecido cierta versatilidad en un sinnúmero de coyunturas. Mientras que desarrollan su actividad política, estos profesionales han tenido la posibilidad de combinarla con la abogacía; asimismo, han podido recurrir a ella en momentos de cambio de las reglas de juego político. Para el vicegobernador de Mendoza entre 1987 y 1991 y gobernador entre 1995 y 1999, el estudio jurídico resultó no sólo un espacio de "ocultamiento de la vida pública" durante los “años duros" del gobierno militar, sino también fue una fuente de recursos económicos que le permitió

${ }^{28}$ Lafalla A. (24 de mayo de 2007). Entrevista al Dr. Arturo Lafalla. Entrevistador: Autora. "sobrevivir" en momentos de interdicción de la actividad política partidaria ${ }^{28}$.

Respecto al número de abogados por partido político se observa que estos profesionales constituyen el grupo mayoritario tanto entre justicialistas, radicales y demócratas. Sin embargo, esta condición parece más importante al interior del partido radical y del partido demócrata, que en el caso del justicialismo. El $34,4 \%$ de los senadores radicales y el $27,2 \%$ de los diputados radicales fueron abogados mientras que el 22,2\% de los senadores demócratas y el 23,5\% de los diputados demócratas desempeñaban esta profesión. Por el contrario, los justicialistas parecieran reclutar un menor número de cuadros dentro de esta actividad: sólo el 15,6\% de senadores y el 17,7\% de los diputados justicialistas son abogados. Esta evidencia sugiere el importante papel que han desempeñado las universidades de derecho, especialmente la Universidad de Mendoza, para reclutar personal político entre radicales y demócratas (Mellado 2015).

Dentro del subgrupo de ocupaciones vinculadas con carreras universitarias, el segundo en importancia es el de los médicos, cuadros "constantes" dentro de los elencos dirigentes. En efecto, en el periodo 1916-1930, los médicos también representaban un grupo de importancia dentro de las instituciones represen- 
tativas, especialmente a través del reclutamiento efectuado por el partido radical. La medicina encarnaba la profesión que "privilegiaba" el ascenso social, por lo que un grupo de inmigrantes escogió estudiar esta carrera (Ferrari 2008, p.121). Esta tendencia se acentuó durante el peronismo. El carácter "político" del rol de los médicos, especialmente en zonas rurales llevaría a que los partidos encontraran atractivo el reclutamiento dentro de este grupo profesional (De Imaz 1964, p.27). En efecto, los médicos han constituido piezas claves para la construcción de redes políticas territoriales al generar lealtades entre los adherentes, ya que son quienes disponen de un mayor conocimiento espacial y geográfico y cuentan con una importante gama de lazos personales.

Asimismo, resulta de interés la distribución de los médicos por partido político: tanto el radicalismo como el peronismo cuenta con una importante presencia de ellos: el 9,1\% de senadores justicialistas y el 6,3\% de senadores radicales han desempeñado esta profesión, partidos que a su vez disponen de una estructura aceitada y reticular en todo el territorio provincial. Si para el caso del justicialismo además contemplamos la distribución geográfica, hay mayor presencia relativa de médicos en el segundo y cuarto distrito, contribuyendo a evidenciar su importante papel en comunidades rururbanas de menor densidad poblacional y donde predominan las actividades agrícolas. Esta situación contrasta con la exhibida por el partido demócrata, que sólo ha colocado un médico como senador. La mayor presencia de médicos dentro del justicialismo puede corresponderse con el rol que han jugado los sindicatos en el reclutamiento de estos profesionales. En especial, los gremios de la sanidad y los gremios estatales parecen constituir espacios propicios para comenzar carreras políticas. Esta situación podría ser similar a la descripta por los profesionales de la educación: mientras que los senadores provenientes de actividades docentes o profesiones vinculadas con la educación representan 10,4\% de los casos en el justicialismo, sólo alcanzan el 3,1\% entre los radicales y el 3,7\% entre los demócratas. Este importante volumen de docentes dentro de la Legislatura esboza la importante vía de acceso que han constituido los sindicatos para ingresar a la actividad política.

Luego, con menor grado de importancia hallamos los grupos vinculados con las profesiones de ingenieros y agrimensores, ingenieros agrónomos y los profesionales vinculados a las ciencias económicas. Una gran parte de estos grupos ingresaron a la actividad política a través de los conocimientos técnicos que le ofrecía la profesión. Por su medio lograron integrar alguna dependencia administrativa, que luego en algunos casos pudo ser revalidada en los cargos ministeriales o incluso en las instituciones legislativas.

Por otro lado, las ocupaciones de aquellos que no alcanzaron un título de educación superior representan también un amplio abanico: empresarios, productores, comerciantes, estudiantes, gremialistas, entre otras. Sin embargo, en un primer acercamiento se advierte la importante presencia del sector de comercio entre el personal político analizado. Los comerciantes representan el $15,8 \%$ del conjunto en la Cámara de Senadores provincial y el 13,9\% en la Cámara de Diputados provincial, mientras que el sector empresario representa el 5,8\% y el 3,2\% en esos mismos espacios. Los comerciantes aparecen como el segundo grupo en importancia luego de los abogados. Si bien esta categoría puede resultar muy heterogénea en su interior, lo cierto es que 27 cargos de senadores de un total de 171 fueron ocupados por comerciantes. De acuerdo a los estudios disponibles, tanto el sector empresario y de comercio comenzó a detentar un peso de significativa importancia entre los elencos políticos en la etapa del peronismo clásico, aunque esta configuración de poder se viera alterada en periodos de corte más conservador ${ }^{29}$. Por último, la distribución de los comerciantes entre los partidos resulta también relevante ya que las tres organizaciones cuentan con un importante reclutamiento dentro de esta activi-
${ }^{29}$ Como señala De Imaz (1964), los escasos ejemplos de empresarios pertenecían a 
empresas importadoras y exportadoras. dad $-15,6 \%$ de dirigentes justicialistas, 17,2\% de dirigentes radicales y el 14,8\% dirigentes demócratas pertenecían a esta actividad en senadores y el $12,5 \%$ de justicialistas, el 12,3\% de radicales y el 23,5\% demócratas en diputados. Para el caso de los diputados provinciales, un rasgo importante de destacar es el alto porcentaje de comerciantes entre los dirigentes del partido justicialista en 1983, que alcanza el $38,8 \%$, tendencia que empieza a revertirse en 1985 y alcanza su máximo descenso en 1987 con el advenimiento de los "jóvenes" políticos profesionales. La preeminencia de comerciantes entre los elencos políticos parece sugerir la importancia de las redes locales de intercambio en la construcción de capital relacional para la obtención de réditos electorales. La actividad vinculada al comercio parece constituir un punto de apoyo importante en la construcción de carreras políticas al trasladar o convertir una importante red comercial en una red política. La profesión de comerciante permite mediar entre diferentes categorías sociales y otorga un importante conocimiento del territorio (Abélès 1989, p.55) .

\section{Conclusiones}

El recorrido trazado en estas páginas buscó delinear el perfil socioprofesional de las élites políticas argentinas a partir de un estudio de caso basado en el reclutamiento del personal político de la provincia de Mendoza entre 1983 y 1999. La recurrencia regular de elecciones a partir de la coyuntura abierta por la transición democrática, y la competencia electoral que encarnó este proceso ameritaron la realización de un ejercicio en torno a explorar los backgrounds sociales de quienes integraron las redes político-administrativas argentinas de las últimas décadas del siglo XX.

El análisis prosopográfico arrojó evidencias empíricas sobre la fisonomía de los grupos políticos. En cuanto a la composición por edad de las élites dirigentes, los perfiles de los legisladores mostraron la confluencia y mixtura de grupos políticos que convergieron en las primeras elecciones de 1983 y 1985, y que luego dieron lugar a un perfil más profesionalizado. Tanto en el radicalismo como en el justicialismo, la presencia de dirigentes de edad avanzada atestiguó la convergencia en la Legislatura de quienes vieron interrumpidas sus carreras políticas por las recurrentes interrupciones institucionales. Pero al mismo tiempo la composición por edad mostró una marcada presencia de diputados jóvenes al interior de los tres partidos mayoritarios, lo que puso de manifiesto las expectativas que despertaba la política como ejercicio profesional en los albores de la etapa abierta en 1983. Esta presencia de elencos jóvenes se visualizó incluso en los diputados que ingresaron al Congreso nacional, quienes aprovecharon una coyuntura favorable de recambio para comenzar sus carreras políticas desde inserciones con un alto grado de exposición pública. Estas carreras meteóricas no sólo estuvieron posibilitadas por un contexto de ruptura que viabilizó vertiginosos ascensos, sino también por la inscripción de estas trayectorias en partidos de alcance nacional que facilitaron el despliegue de carreras políticas de mayor jerarquía. Esta visión contrasta con la exhibida por el partido demócrata. Si bien el porcentaje de jóvenes demócratas que ingresaron a la Legislatura fue similar al de justicialistas y radicales, aspecto que permitió cuestionar una visión común de la escasa capacidad de la organización para recrear liderazgos, su ascenso a los cargos de conducción fue más lento en comparación con los partidos de carácter nacional.

En segundo lugar, los datos agregativos exhiben la alta tasa de rotación del personal político que ingresó a la actividad, lo que ofrece indicios para estipular el tipo de profesionalización política que posibilitó la estabilidad democrática. A diferencia de un conjunto de casos provinciales, donde hay una mayoritaria presencia de grupos consolidados en el poder, como los de las provincias del 
norte del país (Behrend 2011), la alta rotación que muestra el caso analizado exhibe los obstáculos implícitos y explícitos para forjar una carrera política y aleja de pensar a los grupos en el poder como oligarquías enquistadas.

Por otro lado, el análisis cuantitativo también reveló la mayoritaria presencia de hombres en la actividad política, tendencia que sólo logró revertirse parcialmente a través de la ley de Cupo puesta en práctica a partir de 1993. En sintonía con la bibliografía disponible, el caso analizado atestigua que la cuestión de género representaría un obstáculo adicional para forjar una carrera política, ejemplificado a través de la alta rotación de las mujeres en actividad y su dificultad de forjar carreras de carácter nacional. No obstante, esta escasa participación formal - exhibida en los bajos porcentajes de representación alcanzados por las mujeres - no significa que las mujeres no hayan tenido un rol activo en la construcción de los liderazgos políticos provinciales.

Finalmente, los perfiles de los grupos políticos exhibieron algunos rasgos diferenciales con anteriores configuraciones de poder local. Richard Strout (1968) puso de manifiesto que el reclutamiento de los partidos mayoritarios en 1964 - partido radical, justicialista, demócrata y socialista - no ofrecía grandes diferencias en cuanto a los grupos en donde cada partido seleccionaba a sus dirigentes. Las evidencias surgidas a través del estudio de las variables vinculadas con el nivel educativo y actividades previas postulan que la etapa democrática parece haber afinado aún más esa pequeña brecha existente. En efecto, los elencos de los diferentes partidos políticos no presentan grandes diferencias en cuanto a su origen social, sino que exhiben un cambio de perfil paulatino que tiende hacia la mayor presencia de sectores que poseen un título universitario, en detrimento de otro tipo de actividades, como la de comerciantes, representado mayoritariamente en las cohortes de 1983 y 1985. La selección de personal al interior de los partidos políticos a escala provincial muestra un reclutamiento relativamente concentrado entre las clases medias, quienes han encontrado en la actividad política una vía para mantener o acrecentar su posición social, muchas veces amenazada por los procesos de empobrecimiento que atravesaron a estos sectores a partir de la década de 1980. En contraposición, este ejercicio mostró la pérdida de peso del reclutamiento entre sectores medios bajos, especialmente al interior del peronismo como consecuencia del debilitamiento de los sindicalistas en los cargos de conducción del partido y de la incorporación masiva de miembros de la clase media a partir de las experiencias de socialización en la universidad durante los años '70. Esta característica que muestran los perfiles de los diputados provinciales enviados por el justicialismo a la Legislatura, pero más claramente al Congreso de la Nación y a los ministerios ofrecen nuevos indicios sobre una tendencia vigente en las democracias occidentales que atestigua la escasa presencia de sectores populares en los cuerpos representativos y administrativos. Esta experiencia contribuye a observar que la tendencia se percibe incluso en instancias más bajas del poder parlamentario, como las legislaturas provinciales, que a pesar de contar con la presencia de no universitarios, muestran la cada vez más importante selección entre los cuadros con altos niveles de educación y formación.

IVirginia Mellado (virgimellado@ hotmail.com) es Doctora en Historia por la EHESS y la UBA, investigadora de CONICET, y profesora de Sociología Latinoamericana en la Universidad Nacional de Cuyo. Vinculación Institucional: INCIHUSACONICET/UNCuyo, Mendoza, Argentina.

\section{Referencias}

Abélès, M., 1989. Jours tranquilles en 89. Ethnologie politique d'un département français. Paris: Odile Jacob.

Aboy Carlés, G., 2001. Las dos fronteras de la democracia argentina: la reformulación de las identidades políticas de Alfonsín a Menem. Santa Fe: Homo Sapiens. 
Alcántara Sáez, M., 2013. De políticos y política: profesionalización y calidad en el ejercicio público. Perfiles Latinoamericanos, 21(41), pp.19-44. DOI: 10.18504/p12141-019-2013

Almaraz, G., 2010. Ambición política por la reelección en las provincias argentinas. Revista SAAP, 4(2), pp.191-226.

Altamirano, C., 2004. "La lucha por la idea": el proyecto de la Renovación peronista. In M. Novaro \& V. Palermo, eds. Historia Reciente: Argentina en democracia. Buenos Aires: Edhasa.

Barrancos, D., 2002. Inclusión/Exclusión. Historia con mujeres. Buenos Aires: Fondo de Cultura Económica. 2007. Mujeres en la sociedad argentina. Una historia de cinco siglos. Buenos Aires: Sudamericana. 2009. Mujeres, entre la casa y la plaza. Buenos Aires: Sudamericana.

Barry, C., 2009. Evita Capitana. El partido peronista femenino, 1949-1955. Caseros: EDUNTREF.

Behrend, J., 2011. The Unevennes of Democracy at Subnational Level: Provincial Closed Games in Argentina. Latin American Research Review, 46(1), pp.150-176. DOI: 10.1353/lar.2011.0013

Benton, A., 2003. Presidentes fuertes, provincias poderosas: la economía política de la construcción de partidos en el sistema federal argentino. Política y Gobierno, 10(1), pp.103-137.

Bourdieu, P., 1981. La représentation politique. Éléments pour une théorie du champ politique. Actes de la recherche en sciences sociales, 36-37, pp.3-24. DOI: 10.3406/arss.1981.2105 1990. La domination masculine. Actes de la recherche en sciences sociales, 84, pp.2-31. DOI: 10.3406/arss.1990.2947

Bragoni, B., 1999. Los hijos de la Revolución. Familia, negocios y poder en el siglo XIX. Buenos Aires: Taurus.

Buchbinder, P., 2012. Formación de los sectores dirigentes y controversias políticas en el ámbito universitario: el caso de las facultades de derecho, 1890-1912. Boletín del Instituto de Historia Argentina y Americana Dr. Emilio Ravignani, 37, pp.115-142.

Calvo, E. \& Escolar, M., 2005. La nueva política de partidos en Argentina: crisis política, realineamientos partidarios y reforma electoral. Buenos Aires: Prometeo.

Canedo, L., 2002. Héritage en Politique, ou comment acquérir les dispositions et compétences nécessaires aux fonctions de représentation politique (1945-1964). Cahiers du Brésil Contemporain, 47-48, pp.71-119.

Canelo, P., 2011. Acerca de la construcción de carreras políticas en Argentina. Los senadores nacionales en 1973, 1983 y 1989. PolHiS, 7, pp.140-153.

, 2013. Construyendo elites dirigentes. Los gobernadores provinciales durante la última dictadura militar (Argentina, 1976-1983). Anuario del Centro de Estudios Históricos “Prof. Carlos A. Segreti”, 11, pp.323-341.

Cantón, D., 1966. El parlamentarismo argentino en épocas de cambio: 1890, 1916, 1946. Buenos Aires: Editorial del Instituto.

Coradini, O., 2001. In nome de quem? Recursos Sociais no Recrutamento de Elites Políticas. Rio de Janeiro: Relume Dumará.

Dalbosco, H., 2003. Perfil de los funcionarios políticos en la Argentina entre 1983 y 1999. Tesis de Maestría. Buenos Aires: Universidad de San Andrés.

De Imaz, J.L., 1964. Los que mandan. Buenos Aires: EUDEBA.

Eulau, H. \& Koff, D., 1962. Occupational Mobility and Political Career. The Western Political Quarterly, 15(3), pp.507-521. DOI: $10.2307 / 445039$

Ferrari, M., 2008. Los políticos en la Argentina radical. Prácticas políticas y construcción de poder. Buenos Aires: Siglo XXI. 2010. Prosopografía e historia política. Algunas aproximaciones. Antiteses, 3, pp.529-550.

Ferrari, M. \& Mellado, V., 2016. La Renovación peronista. Organización partidaria, liderazgos y dirigentes. Buenos Aires: EDUNTREF.

Gargarella, R.; Murillo, V. \& Pecheny, M., eds., 2010. Discutir Alfonsín. Buenos Aires: Siglo XXI.

Gaxie, D., 1980. Les logiques du recrutement politique. Revue française de science politique, 30(1), pp.5-45. DOI: 10.3406/rfsp. 1980.393877

Gibson, E. \& Suarez Cao, J., 2010. Federalized Party Systems and Subnational Party Competition: Theory and an Empirical Application to Argentina. Comparative Politics, 43(1), pp.21-39. DOI: 10.5129/001041510x12911363510312

Giorgi, G., 2014. Los Factores "Extrapolíticos" de la Carrera Política: Una Aproximación a las Sociabilidades de los ministros de la Nación en la Argentina (1854-2011). Política, 52(2), pp.243-255.

Gutiérrez, R., 2003. Entre movimiento y partido: un análisis de las transformaciones organizativas del peronismo (1983-1995). Política y Gestión, 3, pp.27-76.

Halperin Donghi, T., 1994. La larga agonía de la Argentina peronista. Buenos Aires: Ariel.

Heredia, M.; Gené, M. \& Perelmiter, L., 2012.Hacia una socio-historia del gabinete nacional. PolHis, 5(9), pp.284-290.

ok Hora, R., 2002. Los terratenientes de la pampa argentina. Una historia social y política Buenos Aires: Siglo XXI.

Jones, M.; Saiegh, S.; Spiller, P. \& Tommasi, M., 2002. Amateur Legislators - Professional Politicians: The Consequences of Party-Centered Electoral Rules in a Federal System. American Journal of Political Science, 46(3), pp.656-669. DOI: 10.2307/3088406

Leiras, M., 2007. Todos los caballeros del rey. La integración de los partidos políticos y el gobierno democrático de la Argentina, 1995-2003. Buenos Aires: Prometeo.

Lodola, G., 2009. La estructura subnacional de las carreras políticas en Argentina y Brasil. Desarrollo Económico, 49(194), pp.247-286.

Losada, L., 2008. La alta sociedad en la Buenos Aires de la Belle Époque. Buenos Aires: Siglo XXI. , 2009. Historia de las élites en Argentina. Desde la Conquista hasta el surgimiento del peronismo. Buenos Aires: Sudamericana.

Luci, F., 2016. La era de los managers. Hacer carrera en las grandes empresas del país. Buenos Aires: Paidós. 
Marx, J.; Borner, J. \& Caminotti, M., 2007. Las Legisladoras. Cupos de género y política en Argentina y Brasil. Buenos Aires: Siglo XXI.

Mellado, V., 2015. Socialización y formación de las élites políticas argentinas a fines del siglo XX. Itinerarios universitarios y aprendizajes de la carrera política. Pro-Posições, 26(2), pp.163-185. DOI: 10.1590/0103-7307201507707

,2016a. La representación política en cuestión. Trayectorias de los legisladores de Mendoza en el largo plazo (1946-1999). In S. Mauro \& V. Ortiz de Rozas, eds. Política subnacional en Argentina. Enfoques y problemas. Buenos Aires: UBA.

,2016b. Mendoza. In M. Ferrari \& V. Mellado, eds. La Renovación peronista. Organización partidaria, liderazgos y dirigentes. Caseros: Eduntref.

Mustapic, A.M., 2013. Los partidos políticos en la Argentina: condiciones y oportunidades de su fragmentación. In C. Acuña, ed. ¿Cuánto importan las instituciones? Gobierno, Estado y actores en la política argentina. Buenos Aires: Siglo XXI.

Peleáz, S. \& Valobra, A., 2004. "Sea legisladora". Una representación de las primeras legisladoras argentinas (1949-1955). In K. Ramaciotti \& A. Valobra, eds. Generando el peronismo. Estudios de cultura, política y género (1946-1955). Buenos Aires: Proyecto Editorial.

Perelmiter, L., 2012. La constitución de una autoridad plebeya. El Ministerio "de la pobreza" en la historia reciente. PolHis, 5(9), pp.309-318.

Persello, V., 2007. Historia del radicalismo. Buenos Aires: Edhasa.

Pollak, M., 2000. L'expérience concentrationnaire. Essai sur le maintien de l'identité sociale. Paris: Métailié.

Sawicki, F. \& Mathiot, P., 1999. Les membres des cabinets ministériels socialistes en France (1981-1993): recrutement et reconversion. 1) Caractéristiques sociales et filières de recrutement. Revue française de science politique, 49(1), pp.3-30. DOI: $10.3406 /$ rfsp.1999.395366

Siavelis, P.M. \& Morgenstern, S., 2008. Political Recruitment and Candidate Selection in Latin America: A Framework for Analysis. In P.M. Siavelis \& S. Morgenstern, eds. Pathways to Power. Political Recruitment and Candidate Selection in Latin America. University Park: The Pennsylvania State University Press.

Sineau, M., 2001. Profession : femme politique. Sexe et pouvoir sous la Cinquième République. Paris: Presses de Science Po.

Stone, L., 1971. Prosopography. Daedalus, 100(1), pp.46-71.

Strout, R., 1968. The Recruitment of Candidates in Mendoza Province, Argentina. Tesis de Doctorado. Carolina: University of North Carolina at Chapel Hill.

Wright Mills, C., 1957. La élite del poder. México: Fondo de Cultura Económica.

Vommaro, G., 2015. Las élites políticas de la ciudad de Buenos Aires en sus diferentes escalas.Legisladores y comuneros: un estudio comparativo. In Congreso Internacional "Élites y liderazgo en tiempos de cambio". Salamanca.

Weber, M., 1972. El político y el científico Madrid: Alianza Editorial.

Political elites in the mirror: Socio-professional profiles of political leaders in Argentina (1983-1999)

ABSTRACT Introduction: The aim of this article is to examine the socio-professional characteristics of political groups in Argentina, during a period characterized by democratic stability and electoral competition (1983-1999). The study is based on the analysis of political staff recruitment in Mendoza province to investigate social and group backgrounds, which allows rebuilding a map of political careers possibilities at national and local level. The starting hypothesis was that regular recurrence of elections and the electoral competition after 1983 were contextual factors to encourage the development of political professionalization. Methods: Based on a prosopographical method, the research carried out by the construction of a database, which has 544 entries for positions achieved. The database included national deputies and national senators, ministers, governors, local deputies and local senators, among others. The sources for the construction of database come from National Congress' documents, Legislature of Mendoza, printing press and in-deep interviews. Results: The principal results of the analysis of quantitative variables, like age, gender composition, educational level and occupation before political career, shows off the channels of political elites' recruitment from different social spaces. Discussion: The purpose of this research is to investigate who govern in the democratic Argentina with the view to observing the forms to bring about beliefs into the groups who make decisions. Also, the aspiration is to explore the manner to make and structure political nets between elites, civil servants and bureaucracies. A general overview gives an account of the attributes or conditions to enable or obstruct a political career in the contemporary period. In the end, the research seeks to contribute to the debate of political professionalization in Latin America.

KEYWORDS: political elites; professionalization; democracy; recruitment, prosopography.

This is an Open Access article distributed under the terms of the Creative Commons Attribution Non-Commercial License which permits unrestricted non-commercial use, distribution, and reproduction in any medium provided the original work is properly cited. 